\title{
ADAPTASI PERMAINAN ANGKLUNG KE DALAM PERMAINAN DIGITAL BERBASIS TEKNOLOGI LAYAR SENTUH
}

\author{
Erneza Dewi Krishnasari \\ Universitas Trilogi
}

\begin{abstract}
Abstrak: Angklung adalah salah satu alat musik tradisional Indonesia yang saat ini telah melalui banyak perubahan, baik dalam segi bentuk, maupun fungsi. Awalnya, angklung digunakan untuk aktivitas spiritual, kemudian berkembang menjadi alat musik yang ditampilkan di panggung, serta menjadi alat edukasi. Beberapa tahun belakangan, seiring dengan semakin berkembangnya teknologi, angklung diadaptasi ke media-media digital, salah satunya media dengan teknologi layar sentuh. Dalam mendesain permainan digital dengan angklung sebagai objeknya, beberapa adaptasi diperlukan untuk mengubah metode manual menjadi digital. Penelitian ini disusun melalui pengumpulan data berupa perngambilan gambar teknik-teknik bermain angklung, maupun dari studi pustaka tentang stuktur permainan digital, dan Interaksi dalam teknologi layar sentuh. Setelah semua data terkumpul, perancangan permainan digital angklung dapat dilakukan dengan menggabungkan teori game dan interaksi. Penilitian ini dilakukan untuk memberi rekomendasi pengadaptasian permainan angklung secara manual menjadi permainan musik digital dengan teknologi layar sentuh
\end{abstract}

Kata kunci: permainan musik digital, angklung, teknologi layar sentuh

\begin{abstract}
Angklung is one of Indonesian traditional music instrument that has experienced some changes, in term of function and form. At first, angklung was used for spiritual activities, and then angklung was developed for performance and education activities. Recently, along with technological development, angklung can be adapted into digital medias, for example into a media with technology. In designing an angklung digital game, some adaptations from manual method to digital method are needed. This research is done by collecting images data about angklung playing techniques, and from literature about digital game structure, and interaction in touch screen technology. After all the data is collected, the game can be designed by applying game and interaction theory to the game. This Research is done to provide a recomendation in adapting angklung to a digital rhythm game with touch screen technology.
\end{abstract}

Keywords: digital rhythm game, angklung, touch screen technology

Penulis adalah salah satu staf pengajar di Universitas Trilogi, email: ernezadewi@universitas-trilogi.ac.id 


\section{PENDAHULUAN}

Indonesia adalah negara yang kaya akan keanekaragaman budaya dan etnis. Keanekaragaman budaya daerah tersebut merupakan potensi sosial yang dapat membentuk karakter dan citra budaya tersendiri pada masing-masing daerah, serta merupakan bagian penting bagi pembentukan citra dan identitas budaya suatu daerah. Di samping itu, keanekaragaman merupakan kekayaan intelektual dan kultural sebagai bagian dari warisan budaya yang perlu dilestarikan.

Bagi masyarakat tradisional, alat musik merupakan salah satu bagian dari kehidupan spiritual mereka yang mengiringi acara-acara ritual. Oleh karena itu, bagi mereka, alat musik memiliki makna dan filosofi tersendiri. Tidak berbeda dengan angklung yang merupakan bagian dari alat musik masyarakat Sunda sejak sebelum kerajaaan Sunda muncul, angklung memiliki filosofi dan makna tersendiri yang terus dibawa hingga di era modern.

Berdasarkan situs resmi UNESCO, angklung awalnya merupakan sebuah alat yang digunakan untuk upacara-upacara ritual dengan tangga nada pentatonik. Pada tahun 1938, angklung diubah menjadi alat musik pertunjukan dan pendidikan dengan tangga nada diatonik oleh Daeng Soetigna. Selain dalam bentuk seni pertunjukan, saat ini, dengan teknologi yang telah begitu berkembang, angklung telah diadaptasi ke dalam berbagai bentuk digital, salah satunya ke dalam bentuk rhythm game.

Rhythm game adalah salah satu jenis permainan digital yang dapat digunakan untuk melatih ketepatan ketukan nada tersebut karena permainan ini berbasis pada kemampuan mengikuti irama lagu. Dalam perancangan sebuah permainan digital yang berbasis alat musik tradisional, perlu adanya penyesuaian sedemikian sehingga nilai-nilai yang terdapat dalam alat musik tersebut tetap dapat dirasakan dalam media digital. 


\section{KAJIAN TEORI}

\section{Angklung}

Menurut Nugraha, dkk (2007), berdasarkan cara pembunyiannya, angklung berasal dari kata angkleung-angkleungan yang berarti gerakan pemain yang naik-turun seperti mengapung di atas air, serta bunyi klung yang ditimbulkan oleh instrumen.

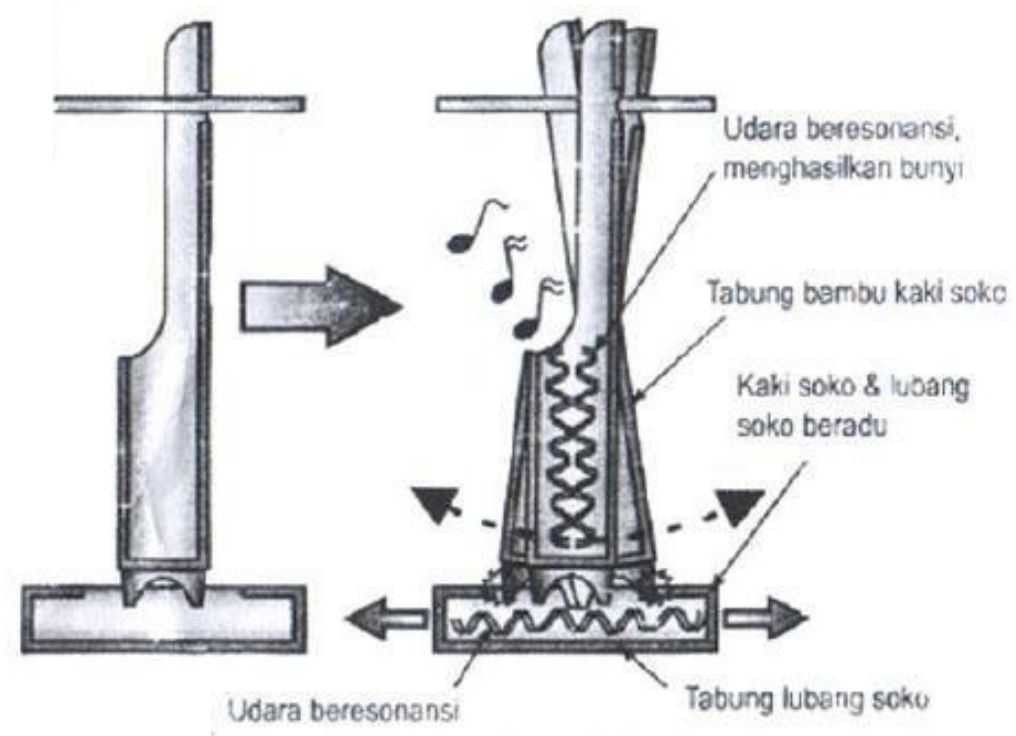

Gamber 1. Cara angklung mengeluarkan suara

Sumber: Nugraha, dkk (2007)

Selanjutnya menurut Nugraha (2007), musik angklung telah ada sebelum kerajaan Sunda berdiri pada tahun 952 pada tahun Saka atau 1030 Masehi. Data ini bersumber dari prasasti yang ditemukan di daerah Cibadak, Kabupaten Sukabumi yang mengisahkan tentang seorang raja Sunda, Sri Jayabhupati. Dalam prasasti ini dikatakan bahwa awal keberadaan angklung tidak terkait dengan adanya kerajaan Sunda. Angklung adalah sebuah alat musik kerakyaan yang berfungsi sebagai media spiritual dan tidak berhubungan dengan duniawi. 
Seiring berjalannya waktu, angklung juga mengalami beberapa perubahan baik dari segi bentuk maupun fungsinya yang dikarenakan oleh pengaruh-pengaruh dari kebudayaan lain. Misalnya Angklung Padaeng yang memiliki tangga nada diatonis yang mengadaptasi dari tangga nada musik barat. Angklung ini diciptakan oleh Daeng Soetigna pada tahun 1938 sebagai media pendidikan musik untuk anak-anak sekolah. Berikut ini adalah perbedaan antara angklung tradisional dengan angklung padaeng (modern):

Tabel 1. Perbandingan Angklung Tradisional dan Angklung Padaeng

\begin{tabular}{|c|c|}
\hline Angklung Tradisional & Angklung Padaeng (Modern) \\
\hline $\begin{array}{c}\text { Untuk tujuan religius atau } \\
\text { ritual }\end{array}$ & $\begin{array}{c}\text { Untuk Tujuan pertunjukan dan } \\
\text { pendidikan }\end{array}$ \\
\hline Alar musik luar ruangan & Alat musik dalam ruangan \\
\hline 5 nada (Pentatonis) & 7 nada (diatonis) \\
\hline Dimainkan 1 orang 1 renteng & $\begin{array}{c}\text { Dimainkan secara bersama - sama, } 1 \\
\text { orang } 1 \text { nada. }\end{array}$ \\
\hline \hline Ukuran besar, nada rendah & Ukuran bervariasi, telah mengalami \\
& simplifikasi \\
\hline
\end{tabular}

Sumber: Nugraha, dkk. (2007)

Selain angklung yang dimainkan secara manual, saat ini angklung telah berkembang ke ranah digital. Misalnya klungbot, angklung yang dapat bergerak memainkan lagu sendiri yang disambung dengan software. Ada juga permainan Bamboo Beat, sebuah arcade game angklung.

Berdasarkan situs resmi Saung Angklung Udjo, angklung modern atau Padaeng dimainkan dengan tiga teknik, yaitu seperti terllhat pada Tabel 2 berikut ini: 
Tabel 2. Teknik-teknik Memainkan Angklung

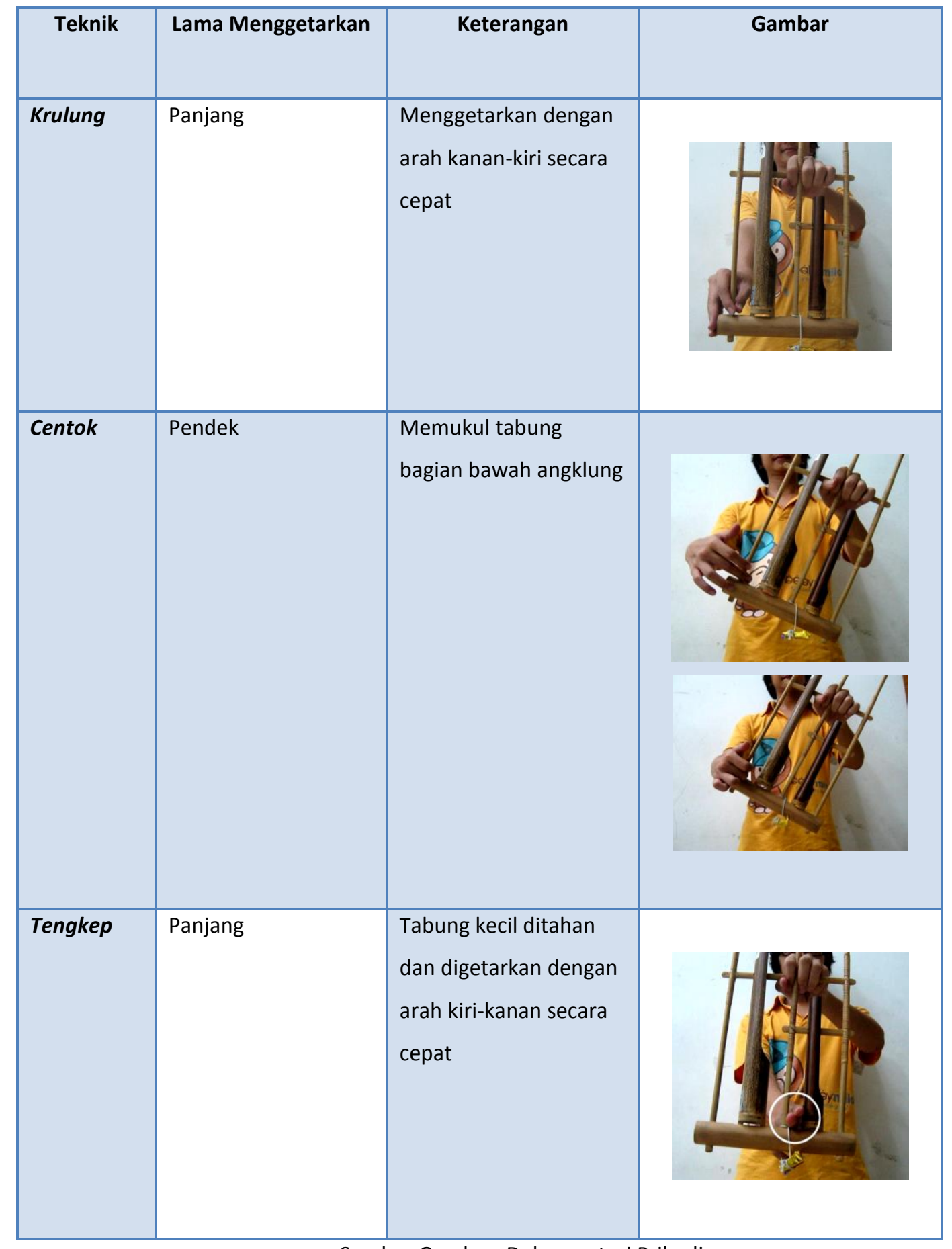

Sumber Gambar: Dokumentasi Pribadi 


\section{Rhythm Game}

Menurut Peng dan Lane (2012), visualisasi yang terdapat dalam rhythm game terdiri dari note yang muncul dan bergerak di layar dengan gaya-gaya tertentu yang disebut sebgai gameplay note. Interaksi dengan note inilah yang melibatkan interaksi tangan dan ketepatan pemain untuk untuk mengeksekusi note yang telah masuk ke ranah hitbox.

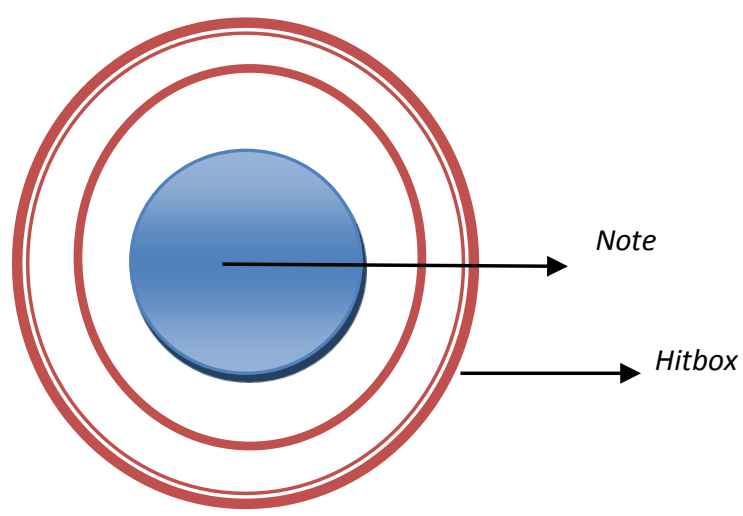

Gambar 2. Note dan Hitbox

Sumber: Peng dan Lane (2012)

Pergerakan notes menuju hitbox dibagi ke dalam 2 jenis, yaitu :

a. Moving Notes to Stationary Hitbox

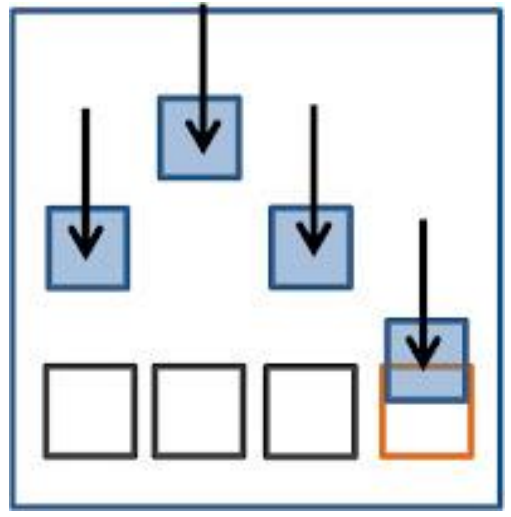

Gambar 3. Notes yang bergerak ke arah hitbox

Sumber : Peng dan Lane (2012) 
b. Moving Hitbox to Stationary Notes

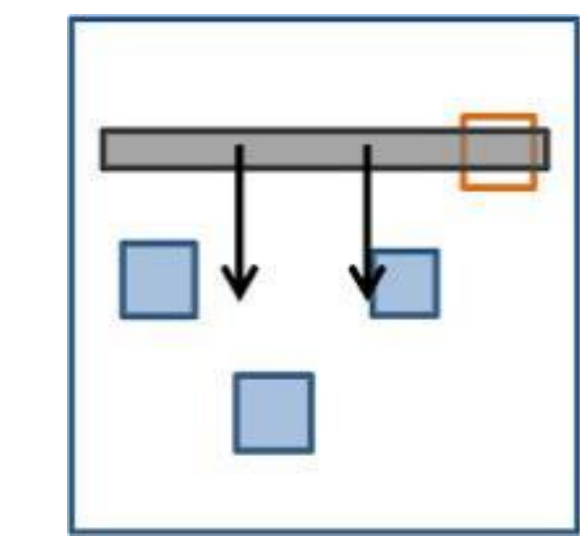

Gambar 4. Hitbox yang berjalan ke arah notes

Sumber: Peng dan Lane, (2012)

\section{Digital Game}

Menurut Crawford (2012), sebuah permainan adalah sesuatu yang sedikit banyak merepresentasikan hal-hal yang terjadi di luar dunia permainan. Sebuah game harus memiliki empat kualifikasi utama. Yaitu:

a. Representation. Sebuah permainan memiliki sebuah sistem formal tertutup yang erat kaitannya dengan dunia nyata. Artinya sebuah permainan merepresentasikan dunia nyata dengan memasukkan unsur emosi dan metafora karena dalam permainan unsur fantasi masih dibutuhkan

b. Interaction. Yang dimaksud dengan interaksi pada permainan dapat bermacam-macam. Sesuatu yang dinamis dan berubah-ubah seiring berjalannya waktu dapat disebut sebagai interaksi. Misalnya saja adanya musik, video, dan animasi. Selain itu adanya interaksi juga dapat ditandai dengan adanya unsur cerita dan dialog di dalam permainan tersebut. Munculnya interaksi dalam sebuah permainan memiliki peran yang cukup penting. Pertama, adanya interaksi berarti memasukkan unsur sosial dan interpersonal pemain terhadap permainan. Kedua, adanya interaksi membuat tantangan menjadi sesuatu yang aktif yang dapat melawan pemain. 
c. Conflict. Konflik adalah elemen intrinsik yang ada pada setiap permainan, baik muncul secara eksplisit maupun implisit, secara kasar maupun halus. Hal ini ada di dalam semua permainan dan erat kaitannya dengan interaksi. Dalam permainan, tugas seorang pemain adalah mencapai tujuannya. Dalam mencapainya, diperlukan beberapa rintangan sehingga tujuan tidak bisa dicapai dengan mudah. Konflik inilah yang akan membuat pemain lebih tertantang dalam mencapai tujuan permainan. Ketika konflik tersebut bersifat pasif, maka itu hanyalah simulasi atau puzzle biasa. Tetapi ketika konflik bersifat dinamis, yaitu bereaksi dan berinteraksi dengan pemain, maka itulah game.

d. Safety. Walaupun dalam sebuah permainan pasti terdapat konflik, namun konflik tersebut tidak boleh membahayakan pemain. Dengan kata lain, dunia permainan adalah dunia di mana pemain dapat pengalaman tentang konflik yang sama seperti di dunia nyata tetapi dengan cara yang aman.

\section{Interaksi pada Teknologi Sentuh}

Touchscreen adalah sebuah tampilan visual elektronik yang memungkinkan pengguna untuk berinteraksi langsung dengan informasi dengan menyentuh area pada layar. Menyentuh ini dapat terjadi dengan jari / tangan atau benda-benda seperti sebagai pena stylus .

Menurut Bhalla (2010), touch screen adalah sebuah benda elektronik berbasis layar berteknologi LCD (Liquid Crystal Display) atau CRT (Cathode Ray Tube) untuk menampilkan sebuah visualisasi dan dapat mendeteksi sentuhan pada layarnya, baik dengan jari atau tangan maunisa maupun dengan bantuan objek lain seperti stylus.

Menurut Engineers Garage (2011), ada beberapa jenis teknologi layar sentuh, diantaranya resistive, capacitive, surface acoustic wave dan infrared. 
Berikut ini adalah contoh-contoh gerakan dasar pada media layar sentuh yang diaplikasikan pada media dengan teknologi tersebut.

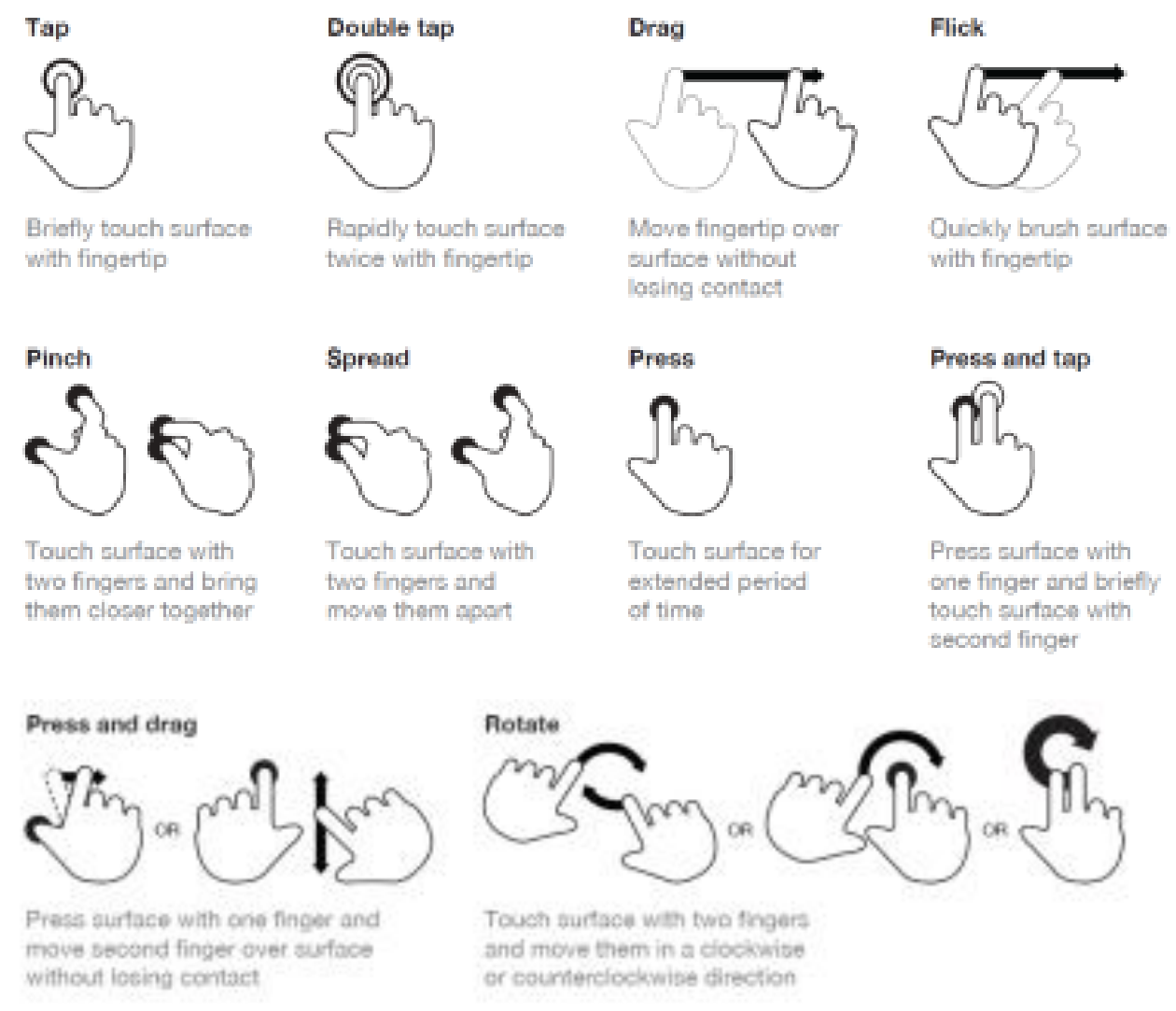

Gambar 5. Gerakan-gerakan pada teknologi Layar Sentuh

Sumber: Villamour dkk; 2010

\section{METODE PENELITIAN}

Untuk menyusun penelitian ini, dilakukan beberapa tahapan, dimulai dengan Studi pendahuluan, yaitu studi literatur tentang angklung, rhythm game dan permainan digital. Kemudian dilanjutkan dengan studi lapangan berupa pengambilan data gambar tentang teknik-teknik bermain angklung. 
Kemudian, angklung sebagai objek peelitian, serta teknologi layar sentuh sebagai media untuk permainan digital, dipetakan berdasarkan variabel pembentuknya. Setelah pemetaan tersebut, dapat dilakukan analisis kebutuhan dan perubahan dari angklung sebagai permainan tradisional, menjadi angklung sebagai permainan digital dalam media berteknologi layar sentuh

\section{HASIL DAN DISKUSI}

\section{Variabel angklung}

Angklung merupakan sebuah alat musik tradisional yang memiliki beberapa ciri khas yang membuat angklung dikenali oleh masyarakat, yaitu:

a. Bentuk

Angklung adalah alat musik yang terdiri dari dua buah tabung bambu berukuran berbeda dan dirangkai menjadi satu kesatuan dengan bilah-bilah bambu lain. Bambu yang dgunakan untuk bahan membuat angklung adalah bambu hitam dan bambu tali. Suara angklung sangat khas karena dihasilkan dari gabungan dua tabung vertikal dan satu tabung horizontal yang beresonansi.

b. Nada

Angklung buhun memiliki nada pentatonik yang terdiri dari 3-5 nada dan memiliki 2 buah interval nada. Sedangkan pada angklung padaeng atau modern, nada-nada pada angklung adalah nada diatonis yang 1 oktafnya berjumlah 12 nada (termasuk nada kromatik). Tinggi rendahnya oktaf nada dapat dihasilkan dari besar dan kecilnya angklung. Angklung yang lebih besar akan menghasilkan nada yang lebih rendah

c. Gestur

Untuk membunyikan angklung terdapat tiga gerakan yang dapat menghasilkan efek suara berbeda, yaitu teknik krulung, centok, dan tengkep. 
d. Metode Permainan

Untuk membuat sebuah lagu, diperlukan beberapa orang untuk memainkan angklung. Masing-masing orang harus bertanggung jawab atas nada yang dimainkannya, karena jika satu nada tidak berbunyi, maka lagu tidak akan terbentuk. Dalam bermain angklung terdapat tanda agar pemain dapat mengetahui kapan mereka harus memainkan nada yang mereka pegang. Tanda ini dapat ditunjukkan baik oleh gerakan dirijen maupun dengan angka dan objek lain seperti isyarat tangan, gambar, dan lain-lain.

\section{Variabel Teknologi Sentuh}

Media layar sentuh memiliki beberapa teknologi berbeda seperti resistive touch, capacitive touch, surface acoustic wave system dan infrared. Untuk membangun sebuah media layar sentuh untuk pengguna, tidak hanya terdiri dari teknologi-teknologi tersebut, melainkan variabel lain yang saling terkait, yaitu:

a. Gestur, merupakan gerakan pemain, dalam hal ini bagian tangan (jari ataupun menggerakkan stylus) untuk melakukan sebuah aksi pada layar

b. Visual, digunakan agar pengguna dapat menentukan objek mana yang harus dikenakan aksi agar reaksi yang diharapkan muncul. Visual juga termasuk tanda-tanda yang digunakan untuk menunjukkan ritme dan menunjukkan kapan seorang permain harus memainkan nada yang mereka pilih.

Dari variabel-variabel angklung dan variabel media layar sentuh, dapat ditarik kesamaan dari segi penggunaan gestur, visual, dan suara. Hubungan variable angklung dengan layar sentuh dapat digambarkan sebagai berikut: 


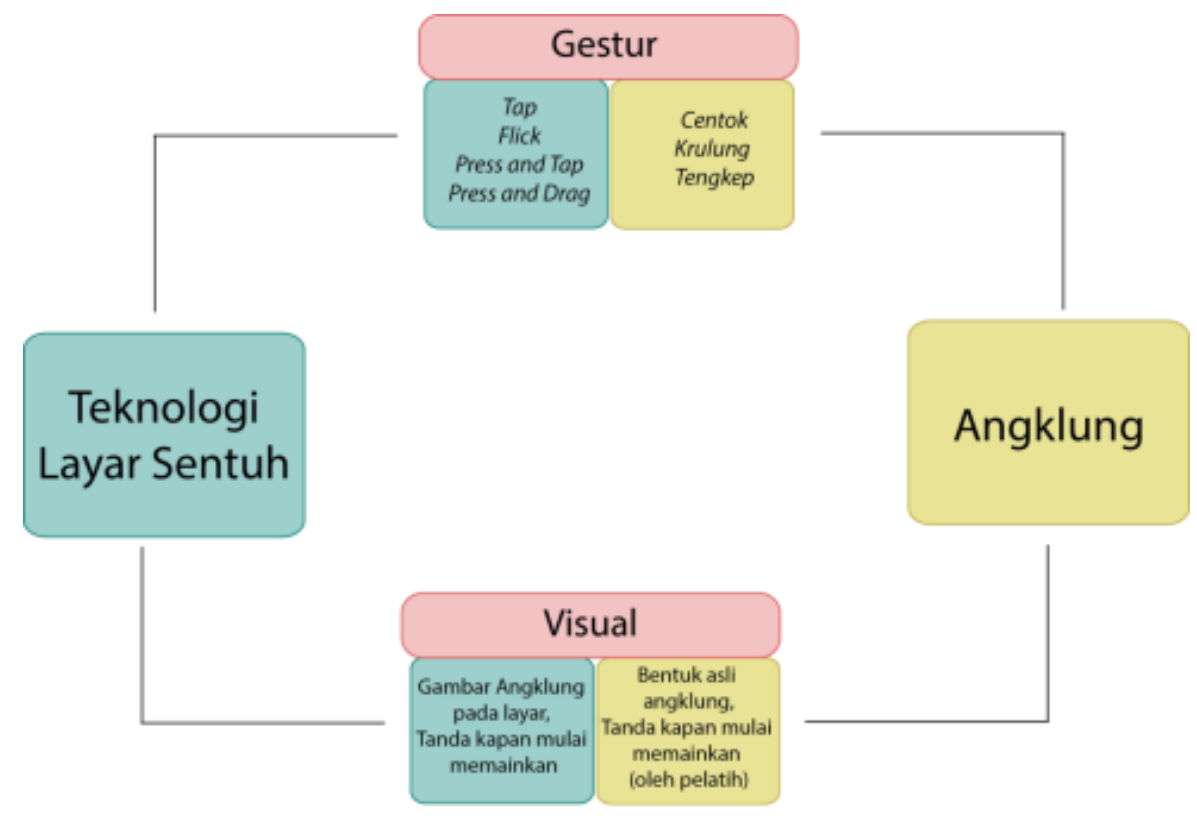

Gambar 6. Hubungan Variabel-variabel Angklung dan Layar Sentuh

Kolaborasi gestur dan visual pada angklung dan pada media dengan teknologi layar sentuh tersebut dapat menghasilkan metode bermain angklung digital seperti:

a. Gestur adaptasi dari gerakan krulung, centok, dan tengkep. Pada gerakangerakan dasar yang dapat diadaptasi antara lain gerakan tap untuk centok, gerakan flick untuk krulung, dan tap and drag atau tap and flick untuk gerakan tengkep.

b. Visualisasi berupa user interface yang digunakan pemain untuk berinteraksi dengan layar dengan gestur tertentu. Visualisasi juga dapat berhubungan dengan metode permainan.

\section{Variabel Permainan Digital}

Rhythm game sebagai sebuah permainan digital tentu mengikuti variabelvariabel yang digunakan dalam sebuah permainan digital pada umumnya. Struktur sebuah rhythm game dilihat dari teori tentang struktur permainan digital yang 
dikemukakan oleh Chris Crawford, yaitu representasi, interaksi, konflik, dan keamanan.

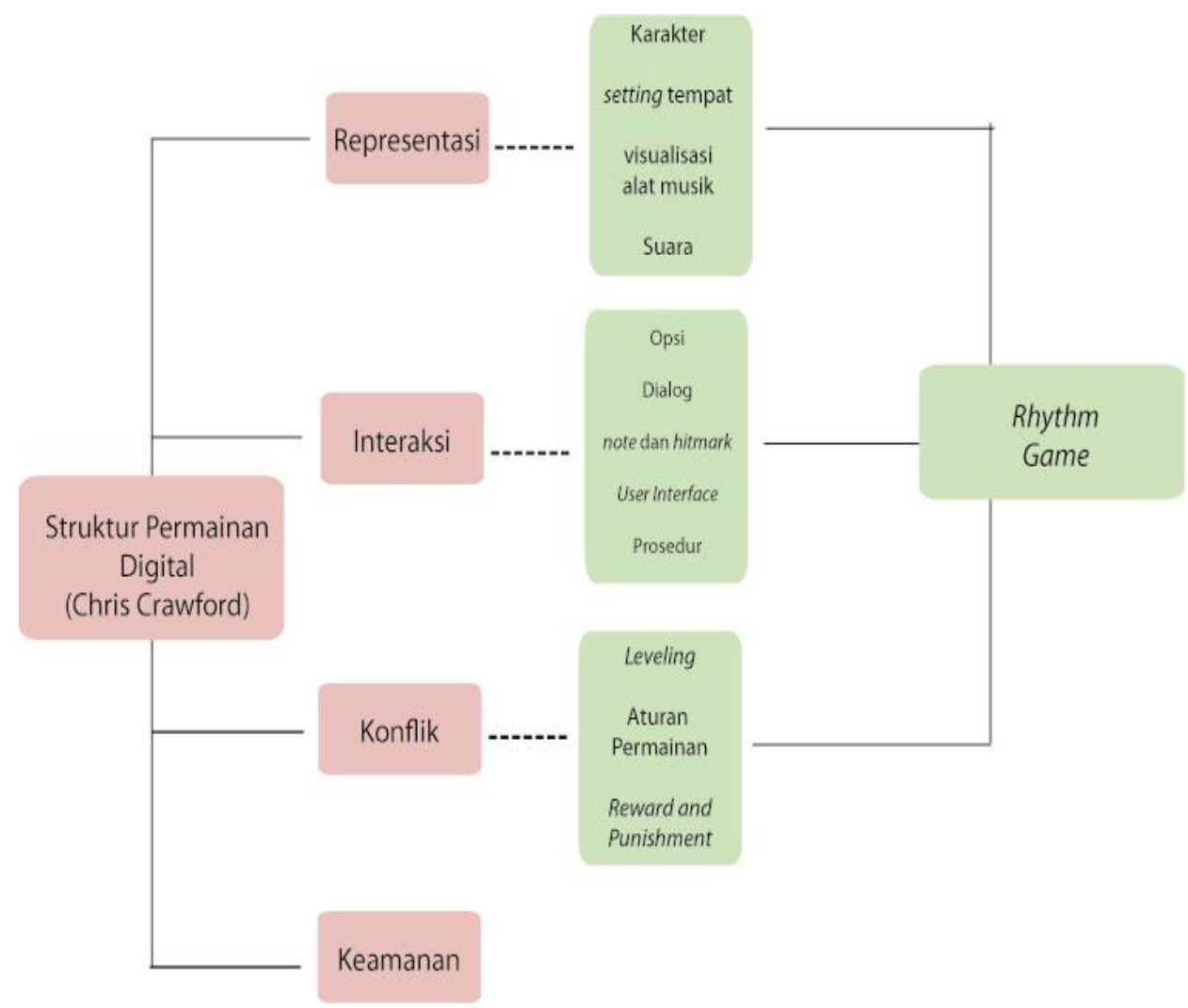

Gambar 7. Struktur Permainan Rhythm Game dalam Struktur Permainan Chris Crawford

\section{Variabel Ketepatan Ketukan Nada}

Pada permainan angklung, yang disebut ketepatan ketukan nada adalah ketika sebuah nada dibunyikan pada ketukan yang tepat. Untuk mendapatkan ketukan yang tepat, saat latihan tahap awal, pemain dapat melihat kapan tepatnya angklung dimainkan dengan melihat angka-angka pada partitur. Pelatih akan menunjuk angka tersebut, dan pemain harus membunyikan angklung tepat ketika pelatih menunjuk nada. Pada latihan tahap selanjutnya, di mana pemain dapat membaca partitur sendiri, tanda ketukan berasal dari suara yang dibuat oleh 
pelatih, misalnya tepukan tangan atau gerakan tongkat memukul. Pada latihan tahap selanjutnya, tanda ketukan dapat dilihat dari gerakan tangan pelatih atau dirijen saat penampilan.

Dalam rhythm game ketepatan ketukan adalah ketika pemain tepat memberikan aksi pada tombol saat note memasuki ranah hitmark. Ketepatan ini biasanya ditandai dengan efek visual cahaya, tulisan, ataupun efek suara.

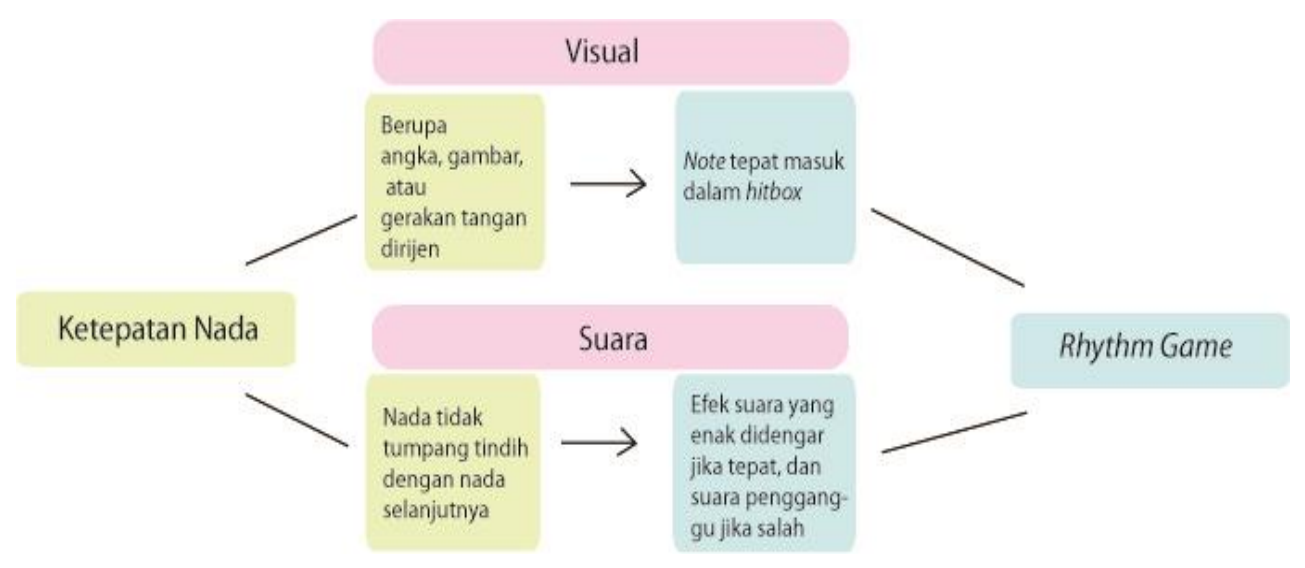

Gambar 8. Ketepatan Ketukan pada Rhythm Game dan Angklung

\section{KESIMPULAN}

Dari beberapa variabel yang telah dijelaskan, yaitu mengenai hubungan variabel-variabel angklung dengan struktur permainan digital oleh Chris Crawford, visualisasi, interaksi, serta teknologi, maka permainan angklung digital terdiri dari :

a. Representasi, yang berupa karakter pemain angklung, seting tempat bermain angklung, bentuk angklung, maupun suara yang dihasilkan.

b. Interaksi berupa gerakan angklung yang telah diadaptasi menjadi gerakan untuk layar sentuh. Interaksi tidak hanya dilakukan lewat gerakan, tetapi juga lewat suara (penanda jika salah atau benar), dan visual (interaksi antara note dan hitmark)

c. Konflik yang dapat berupa perbedaan tingkat kesulitan atau sistem leveling, serta reward and punishment. 
Memasukkan angklung sebagai objek atau konten dari sebuah media digital dapat dilakukan dengan cara memasukkan variabel-variabel angklung ke dalam struktur permainan digital yang menggunakan teknologi layar sentuh. Hal ini dilakukan sebagai bentuk penyederhanaan dari angklung namun tetap tidak kehilangan konten permainannya, sehingga pemain tetap dapat merasakan permainan angklung yang sebenarnya, dalam bentuk perangkat layar sentuh yang mudah dibawa.

\section{DAFTAR PUSTAKA}

Bhalla, Mudit Ratana and Anan Fardhan Bhalla. 2010. Comparative Study of Various Touchscreen Technology. International Journal of Computer Application Vol. 6, No. 8 (p. $12-18$ )

Crawford, Chris. 2012. Chris Crawford on Game Design 2nd Edition. USA: New Riders

Emmons, Stephen D. 2009. Handbook of Basic Music Theory. Texas: Angelo State University

Engineers Garage.2011. Touchscreens or Human Machine Interface. Diakses dari http://www.engineersgarage.com/articles/touchscreen-technologyworking?page $=1$ tanggal 18 Februari 2016

Nugraha, Hari, dkk. 2007. Desain Angklung Tradisional dan Modern. Jurnal Ilmu Desain FSRD ITB (2) hal. 15-30

Peng, Philip H dan Stephen H. Lane. 2012. Designing Rhythm Game Interfaces for Touchscreen Devices. United States: Dept. of CIS - Senior Design 2011-2012 Saffer, Daniel. 2007. Designing for Interaction. USA: New Riders.

Saung Angklung Udjo. 2012. Bermain Angklung. Diakses dari http://www.angklung-udjo.co.id/id/angklung/playing-angklung/ tanggal 10 Juni 2013 
UNESCO. 2010. Indonesian Angklung. Diakses dari

http://www.unesco.org/archives/multimedia/?s=films details\&pg=33\&id=1

$\underline{681}$ tanggal 20 Oktober 2012

Villamour, Craig, Dan Willis; and Luke Wroblewski. 2010. Touch Gesture Reference

Guide. Diakses dari http://www.lukew.com/touch , tanggal 10 Juni 2013 